\title{
Desenvolvimento inicial de trigo sob doses de nitrogênio em Latossolo Vermelho de Cerrado
}

\author{
William Pietro-Souza ${ }^{1}$, Edna M. Bonfim-Silva ${ }^{1}$, Alessana F. Schlichting ${ }^{1} \&$ Matheus de C. Silva ${ }^{1}$
}

\section{RESUMO}

As condições de solo, clima, topografia e variedades adaptadas, têm favorecido o cultivo de trigo no Cerrado; contudo, no que concerne à adubação nitrogenada, ela é responsável pelo incremento de produção. Assim, o objetivo deste estudo foi avaliar o desenvolvimento inicial e a produção de massa seca de plantas de trigo cv. Guamirim adubado com nitrogênio em Latossolo Vermelho do Cerrado. O experimento foi conduzido em casa de vegetação da Universidade Federal do Mato Grosso - Campus Universitário de Rondonópolis, em vasos com capacidade para $5 \mathrm{dm}^{3}$. O delineamento experimental foi o inteiramente casualizado com seis doses de nitrogênio $\left(0,80,160,240,320\right.$ e $\left.400 \mathrm{mg} \mathrm{dm}^{-3}\right)$, cinco repetições e cinco plantas por vaso. Os períodos de avaliações foram: 26, 33, 40 e 47 dias após a emergência, determinou-se: número de folhas e perfilhos, altura de planta, massa seca da parte aérea e raízes. A adubação nitrogenada influencia o desenvolvimento das plantas de trigo em todos os períodos avaliados. As melhores respostas do trigo à adubação nitrogenada ocorrem nas doses entre 80 a 195,6 $\mathrm{mg} \mathrm{dm}^{-3}$.

Palavras-chave: Triticum aestivum L., crescimento, ureia

\section{Initial development of wheat under different nitrogen levels in an Oxisol of the 'Cerrado'}

\begin{abstract}
The soil conditions, climate, topography and adapted varieties have favored the cultivation of wheat in the 'Cerrado'. However, regarding the nitrogen fertilization, it is considered the main factor for increasing production. The objective of this study was to evaluate the initial development and dry mass production of wheat plants cv. Guamirim fertilized with nitrogen in the 'Cerrado' Oxisol. The experiment was carried out in a greenhouse at the University of Mato Grosso - Campus of Rondonópolis, in recipients of $5 \mathrm{dm}^{3}$. The experimental design was completely randomized with six levels of nitrogen $(0,80,160,240,320$ and $400 \mathrm{mg} \mathrm{dm}^{-3}$ ), five replications with five plants per pot. The evaluation periods were: 26, 33, 40 and 47 days after emergence, where the number of leaves and tillers, plant height, dry mass of shoots and roots were determined. Nitrogen fertilization affected the wheat plant development for all evaluated periods. The best responses of wheat to nitrogen fertilization occurred at doses ranging from 80 to $195.6 \mathrm{mg} \mathrm{dm}^{-3}$.
\end{abstract}

Key words: Triticum aestivum L., growth, urea 


\section{INTRODUÇÃO}

O trigo (Triticum aestivum L.) cultura com história milenar, é um dos principais cereais utilizados na alimentação humana devido às suas propriedades nutricionais. Seu consumo é praticado sob diferentes formas, tais como, bolos, biscoitos, pães, massas em geral. Mundialmente, os maiores produtores são os Estados Unidos, Comunidade Europeia, Rússia e China. No Brasil é cultivado, geralmente, em áreas de clima temperado, como os estados do Sul do país; entretanto, tem-se expandido para os estados do Centro-Oeste e Sudeste.

Condições climáticas favoráveis, com radiação solar abundante e relevo plano, propiciam a utilização de implementos agrícolas e colocam o cerrado brasileiro em destaque no cenário agrícola, repercutindo em aumento de áreas agricultáveis com inserção de novas culturas, entre elas o trigo, cuja área plantada no cerrado aumentou significativamente nos anos recentes, sustentada, sobretudo pelo criterioso manejo do solo e pelo melhoramento genético de plantas de trigo responsivas às adubações, sobremaneira à adubação nitrogenada (Trindade et al., 2006; Teixeira Filho et al., 2007; CONAB, 2011).

O nitrogênio se caracteriza como um dos principais fatores limitantes ao crescimento e desenvolvimento das plantas (Meneghin et al., 2008) participando na constituição de substâncias determinantes da qualidade e no desenvolvimento de funções metabólicas essenciais, tais como a síntese proteica (Pöttker \& Roman, 1998).

Solos brasileiros não suprem totalmente a demanda do nutriente sendo essencial, portanto, a complementação com fertilizantes nitrogenados. Todavia, a adubação requer cuidados no que concerne à época e às doses de aplicação. Pequenas doses de nitrogênio podem limitar a produtividade mas altas doses podem levar ao acamamento, dificultar a colheita e provocar queda na produção (Teixeira Filho et al., 2010).

Cazeta et al. (2007) relatam que deficiência no suprimento de nitrogênio pode comprometer os processos de crescimento e reprodução das plantas e que aplicações eficientes de nitrogênio estão intrinsecamente relacionadas ao solo, clima e à própria planta.

Yano et al. (2005) apontam que da emergência até a emissão da sétima folha este é o período crítico para cultura do trigo, ou seja, é justamente nessa época que as plantas carecem da maior demanda de nitrogênio.

Durante os estádios iniciais o nutriente é necessário para potencializar o número máximo de espiguetas por espiga e, consequentemente, o número de grãos por espiga, enquanto nos estádios finais do período o nitrogênio é crítico para determinar o número de colmos por área (Bredemeier \& Mundstock, 2001).

As quantidades e a fonte adequadas de nitrogênio são essenciais para incrementar a produtividade e a qualidade do trigo promovendo o máximo potencial de produtividade (Megda et al., 2009). Neste sentido, trabalhos apontam a relação positiva entre nitrogênio e trigo.

Trindade et al. (2006) averiguaram que doses de nitrogênio afetaram significativamente a produtividade do trigo cultivado em solo de Cerrado. Teixeira Filho et al. (2007) observaram, em diferentes genótipos, que doses de nitrogênio foram suficientes para aumentar o teor de nitrogênio foliar, o número de espigas por metro, a massa de 100 grãos e a produtividade de grãos.
Espindula et al. (2010) verificaram resposta quadrática na produtividade dos grãos de trigos adubados com nitrogênio, com ponto de máxima de $5.032 \mathrm{~kg} \mathrm{ha}^{-1}$, estimado na dose de $96,8 \mathrm{~kg} \mathrm{ha}^{-1}$, para a cultivar Pioneiro.

Estudos que abordem a resposta do trigo à adubação nitrogenada carecem de informações, especialmente na região de cerrado. Assim, o objetivo do presente estudo foi avaliar os efeitos das doses de nitrogênio no desenvolvimento inicial e na produção de massa seca de plantas de trigo em Latossolo Vermelho no Cerrado.

\section{Material e Métodos}

O experimento foi conduzido em casa de vegetação na Universidade Federal de Mato Grosso, Campus Universitário de Rondonópolis, MT, no período de abril a junho de 2011. As sementes de trigo da cv. Guamirim foram plantadas em vasos com capacidade para $5 \mathrm{dm}^{3}$ de solo coletado na profundidade $0-20 \mathrm{~cm}$ em área de cerrado nativo na região de Rondonópolis.

O solo utilizado foi classificado como Latossolo Vermelho de textura média (EMBRAPA, 2006) apresentando as seguintes características químicas e físicas: $\mathrm{pH}\left(\mathrm{CaCl}_{2}\right): 4,1 ; \mathrm{P}: 2,4 \mathrm{mg}$ $\mathrm{dm}^{-3} ; \mathrm{K}: 28 \mathrm{mg} \mathrm{dm}^{-3}$; Ca: $0,3 \mathrm{cmol}_{\mathrm{c}} \mathrm{dm}^{-3} ; \mathrm{Mg}: 0,2 \mathrm{cmol}_{\mathrm{c}} \mathrm{dm}^{-3}$; Al: $1,1 \mathrm{cmol}_{\mathrm{c}} \mathrm{dm}^{-3}$; CTC: $5,9 \mathrm{cmol}_{\mathrm{c}} \mathrm{dm}^{-3}$; saturação por bases: 6,5\%; matéria orgânica: $22,7 \mathrm{~g} \mathrm{dm}^{-3}$; areia: $549 \mathrm{~g} \mathrm{~kg}^{-1}$; silte: 84 $\mathrm{g} \mathrm{kg}^{-1}$; argila $367 \mathrm{~g} \mathrm{~kg}^{-1}$. Realizou-se a adubação com fósforo $\left(\mathrm{P}_{2} \mathrm{O}_{5}\right)$ e potássio $\left(\mathrm{K}_{2} \mathrm{O}\right)$ utilizando-se 200 e $150 \mathrm{mg} \mathrm{dm}^{-3}$ respectivamente. A correção do solo foi realizada pelo método de saturação por bases com elevação para $70 \%$ e, após 20 dias, ocorreu a semeadura. A umidade do solo nos vasos foi mantida por meio gravimétrico atendendo a $70 \%$ de capacidade máxima de retenção de água do solo.

O experimento foi realizado em delineamento inteiramente casualizado com seis doses de nitrogênio $(0,80,160,240,320$ e $400 \mathrm{mg} \mathrm{dm}^{-3}$ ) e cinco repetições. A adubação nitrogenada foi parcelada em duas vezes iguais, ou seja, aos 7 e 15 dias após a emergência (DAE) das plantas utilizando-se, como fonte de nitrogênio, a ureia.

Foram utilizadas vinte sementes por vaso cuja emergência das plantas ocorreu aos cinco dias após a semeadura. O desbaste foi realizado três dias após a segunda etapa da adubação nitrogenada (18 DAE) deixando-se cinco plantas por vaso as quais foram cultivadas até o início da emissão da folha bandeira (47 DAE).

O número de perfilhos, folhas e a altura das plantas, foram avaliados aos 26, 33, 40 e 47 DAE. A massa seca da parte aérea e das raízes foi determinada aos 47 DAE das plantas sendo determinada após secagem em estufa com circulação forçada a $65-70^{\circ} \mathrm{C}$, até massa constante. Com vista à separação das raízes do solo, utilizou-se um recipiente com água cujo solo, contendo as raízes, foi lavado em peneira $(2 \mathrm{~mm})$ para minimizar as perdas das mesmas.

A partir da massa seca da parte aérea e das raízes das plantas estimou-se a relação parte aérea/raiz (MSPA/MSR). Todos os resultados foram submetidos às análises de variância e teste de regressão a $5 \%$ de probabilidade, pelo programa Sisvar (Ferreira, 2008). 


\section{Resultados E Discussão}

O trigo respondeu significativamente à adubação nitrogenada com variação na altura de plantas (Figura 1). As maiores alturas de plantas de trigo ocorreram utilizando-se doses de nitrogênio compreendidas entre o intervalo de $120-180 \mathrm{mg} \mathrm{dm}^{-3}$ nas épocas avaliadas, exceto aos 47 DAE, observando-se a maior altura de plantas na dose de nitrogênio de $300 \mathrm{mg} \mathrm{dm}^{-3}$.

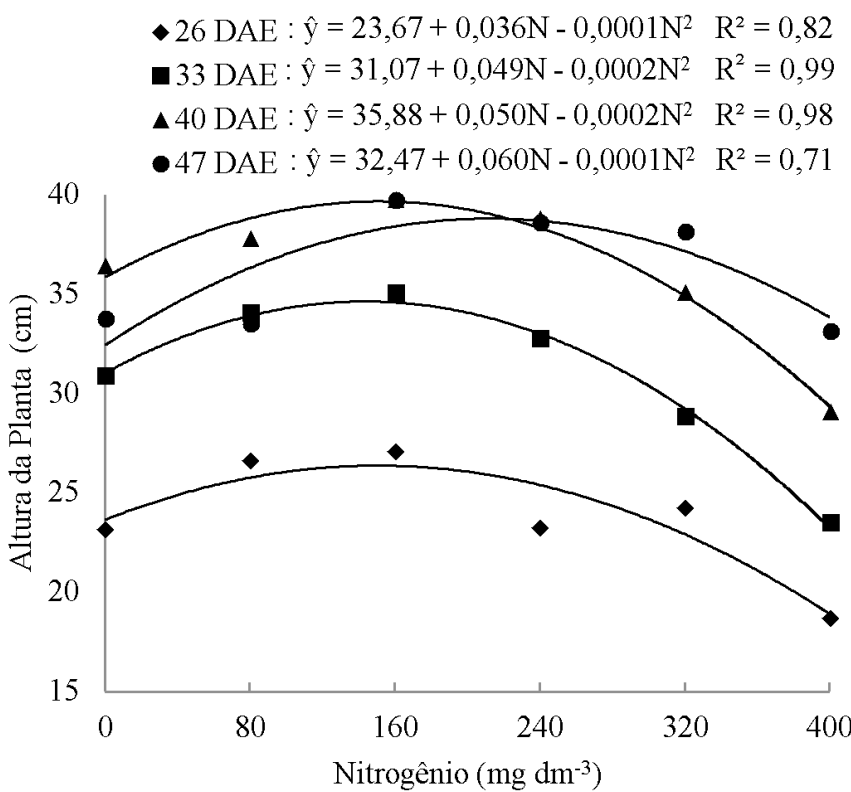

Figura 1. Altura de plantas de trigo em épocas de avaliação (26, 33, 40 e 47 dias após emergência DAE) em função de doses de nitrogênio em Latossolo Vermelho de Cerrado

Previam-se esses resultados já que a oferta de nitrogênio influencia no alongamento do caule em cereais, porém este atributo não é favorável visto que o maior comprimento das plantas pode refletir, geralmente, em maior predisposição ao acamamento (Espindula et al., 2010).

Ribeiro Júnior et al. (2007) verificaram que os genótipos BRS254 e BRS264 tenderam a diminuir a altura de plantas em doses de nitrogênio superiores a $50 \mathrm{~kg} \mathrm{ha}^{-1} \mathrm{e}$ para os genótipos PF013452 e CPAC02172 houve ajuste ao modelo linear de regressão com incremento em altura de plantas até o uso da maior dose de nitrogênio que corresponde a $150 \mathrm{~kg} \mathrm{ha}^{-1}$. Espindula et al. (2010) também obtiveram aumento linear da altura de plantas de trigo em relação às doses de nitrogênio.

O incremento nas doses de nitrogênio proporcionou aumento significativo no número de folhas em todas as avaliações (26, 33, 40 e 47 DAE); no entanto, a máxima produção foi observada aos $47 \mathrm{DAE}$, referente à dose de nitrogênio de $195,6 \mathrm{mg} \mathrm{dm}^{-3}$ (Figura 2).

O aumento no número de folhas associado ao seu tamanho contribui para o aumento da área foliar e, em contrapartida, interfere positivamente na interceptação da energia solar incidente promovendo, por conseguinte, maior assimilação de carbono o qual pode contribuir significativamente para aumentar o acúmulo de massa seca pelas plantas (Cruz et al., 2007).

O perfilhamento das plantas de trigo foi influenciado pelas doses de nitrogênio, em todas as épocas de avaliações (Figura

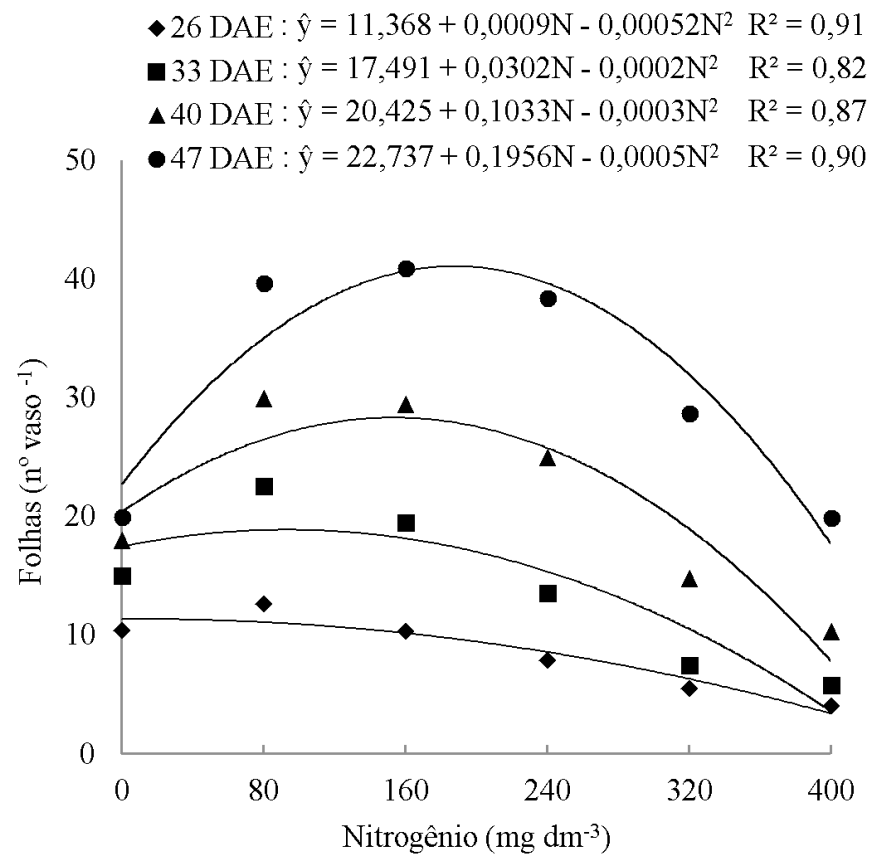

Figura 2. Número de folhas de plantas de trigo em épocas de avaliação $(26,33,40$ e 47 dias após emergência - DAE) em função de doses de nitrogênio em Latossolo Vermelho de Cerrado

3). Os maiores números de perfilhos foram observados nas doses de nitrogênio de 29,41; 105,88; 169,02 e 193,13 $\mathrm{mg} \mathrm{dm}^{-3}$ nas avaliações de 26, 33, 40 e 47 DAE, respectivamente. Esses resultados discordam dos obtidos por Penckowski et al. (2009) que quantificaram o efeito das doses de nitrogênio e de redutor de crescimento; os autores verificaram, também, que na ausência de redutor de crescimento a adubação nitrogenada não proporcionou aumento do número de perfilhos em plantas de trigo.

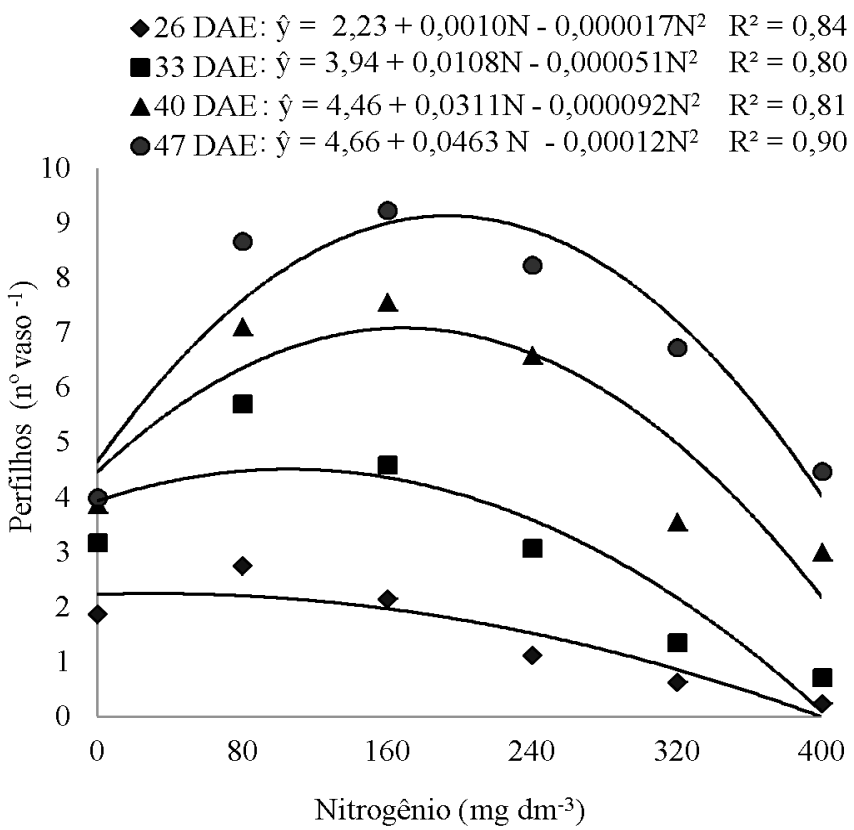

Figura 3. Perfilho de plantas de trigo em épocas de avaliação (26, 33, 40 e 47 dias após emergência DAE) em função de doses de nitrogênio em Latossolo Vermelho de Cerrado 
Martuscello et al. (2006) observaram, ao avaliarem o Panicum maximum $\mathrm{x}$ Panicum infestum $\mathrm{cv}$. Massai submetido a quatro doses de nitrogênio, aumentos de 26,30 e $61 \%$ no número de perfilhos para as doses de nitrogênio de 40,80 e $120 \mathrm{mg} \mathrm{dm}^{-3}$, respectivamente, em relação às plantas que não receberam adubação nitrogenada.

Bonfim-Silva \& Monteiro (2006) estudando a interação de doses de nitrogênio e enxofre em características produtivas em capim-braquiária (Brachiaria decumbens) observaram que o número de perfilhos respondeu significativamente ao nitrogênio. $\mathrm{Na}$ avaliação do efeito isolado do nitrogênio os autores constataram que no perfilhamento no segundo crescimento do capim-braquiária a dose de nitrogênio que proporcionou o máximo perfilhamento foi de $325 \mathrm{mg} \mathrm{dm}^{-3}$. Entretanto, no terceiro crescimento a dose de nitrogênio que proporcionou a máxima produção de perfilhos foi de $297 \mathrm{mg} \mathrm{dm}^{-3}$.

Para Ramos (1973) o nitrogênio deve estar disponível no estádio de perfilhamento, período no qual o mesmo é muito importante na determinação do número de perfilhos por planta, espigas por planta e de grãos por espiga de trigo.

Em estudo realizado por Fioreze (2011) constatou-se que cultivares de trigo diferem substancialmente na sua capacidade de emissão de perfilhos, no ciclo, na arquitetura de planta e no potencial produtivo. Essas diferenças podem interferir na capacidade de absorção, assimilação e conversão do nitrogênio, o que pode ter influência na produção de grãos. Além disto, existe o poder compensatório (Espindula et al., 2010) no qual o aumento de uma característica pode limitar a outra, ou seja, quanto maior o número de perfilhos maior também será a quantidade de folhas e, em consequência, a competição por fotoassimilados se acentua no interior das plantas.

A produção de massa seca da parte aérea do trigo aumentou com as doses de nitrogênio (Figura 4) com máxima produção de massa seca na dose de nitrogênio de $165 \mathrm{mg} \mathrm{dm}^{-3}$. Esses resultados estão de acordo com os observados por Viana \&

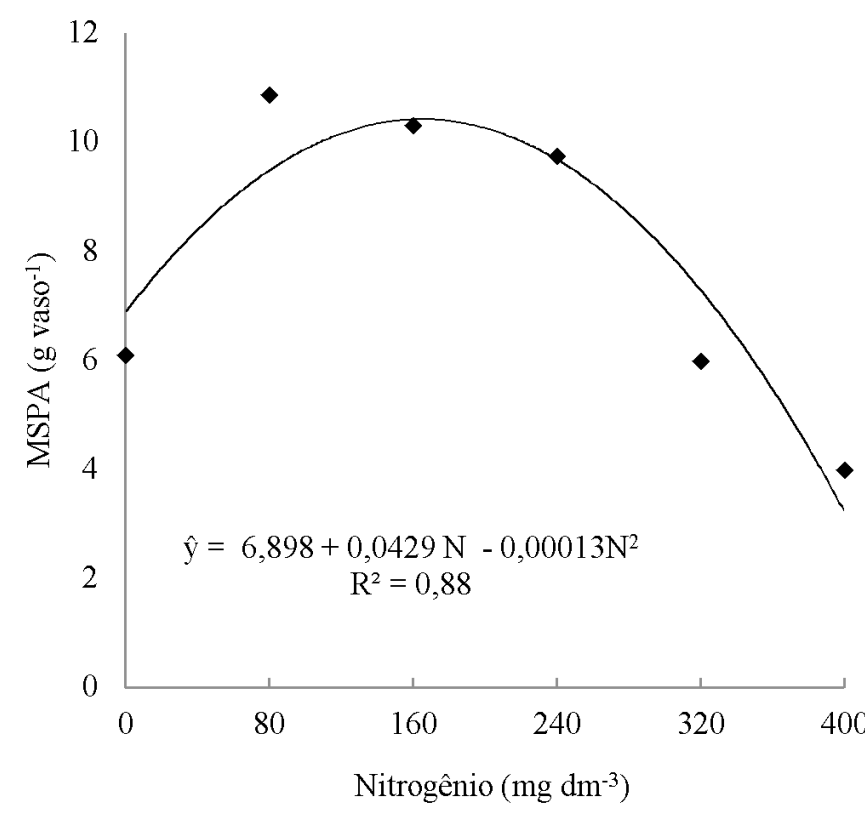

Figura 4. Massa seca da parte aérea (MSPA) de plantas de trigo aos 47 dias de crescimento em função das doses de nitrogênio em Latossolo Vermelho do Cerrado
Kiehl (2010) que encontraram máxima produção da massa seca da parte aérea na cultura do trigo na dose de nitrogênio de 251 $\mathrm{mg} \mathrm{dm}{ }^{-3}$ associada à maior dose de potássio $\left(200 \mathrm{mg} \mathrm{dm}^{-3}\right)$.

Coelho et al. (1998) relataram, ao utilizar quatro doses de nitrogênio $\left(30,60,90\right.$ e $\left.120 \mathrm{~kg} \mathrm{ha}^{-1}\right)$ em cobertura no trigo Embrapa-22 que os pontos máximos de produção de massa seca da parte aérea apresentaram resposta quadrática às doses de nitrogênio de $94 \mathrm{e} 97 \mathrm{~kg} \mathrm{ha}^{-1}$ com máximas produtividades de 10.116 e $13.040 \mathrm{~kg} \mathrm{ha}^{-1}$ em 1995 e 1996, respectivamente.

Aumentos de massa seca da parte aérea em função de doses de nitrogênio são geralmente aguardados, uma vez que o nutriente contribui para o crescimento vegetativo das plantas atuando principalmente nas taxas de iniciação e expansão foliar, no tamanho final das folhas e no alongamento do caule (Schröder et al., 2000).

Na produção de massa seca de raiz houve efeito significativo das doses de nitrogênio (Figura 5) com máxima produção na dose de nitrogênio de $54,44 \mathrm{mg} \mathrm{dm}^{-3}$. A carência de trabalhos com trigo relacionados a doses de nitrogênio, não permitiu comparações, porém para outras culturas é relatada influência do nitrogênio na produção de massa seca de raiz, tal qual observado por Rodrigues et al. (2007) em capim-xaraés com máxima produção de massa seca de raiz na dose de nitrogênio de $159 \mathrm{mg} \mathrm{dm}^{-3}$.

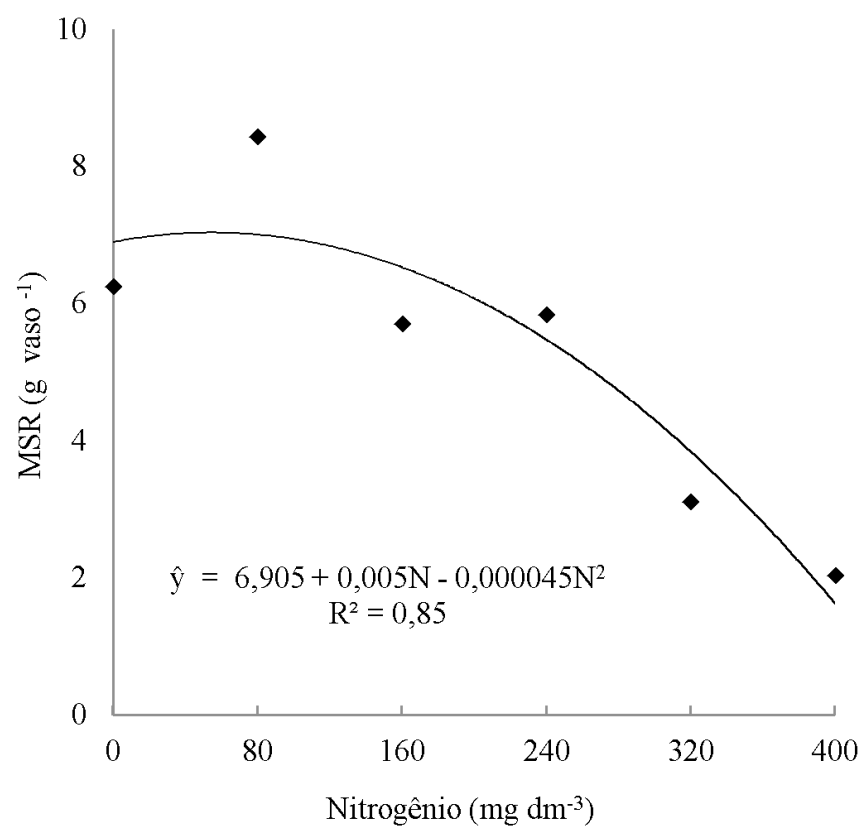

Figura 5. Massa seca de raiz (MSR) de planta de trigo aos 47 dias de crescimento em função das doses de nitrogênio em Latossolo Vermelho de Cerrado

Silveira et al. (2011) estudando interação de nitrogênio e enxofre em capim-braquiária (Brachiaria decumbens) encontraram efeito significativo isolado da adubação nitrogenada na produção de massa seca de raiz cuja equação se ajustou ao modelo quadrático. Por outro lado, Martuscello et al. (2006) não constataram influência do nitrogênio no sistema radicular de capim-massai.

A produção da massa seca de raiz nas menores doses de nitrogênio pode estar relacionada à baixa disponibilidade 
desse nutriente no solo, que induz o crescimento radicular das plantas deixando suas raízes mais longas, porém mais finas e, com a falta de nutrientes, as raízes tendem a se expandir e explorar o máximo possível o volume do solo (Martuscello et al., 2006).

Segundo Lemaire et al. (1997) as plantas que crescem em condições de baixa disponibilidade de nitrogênio apresentam baixa atividade meristemática da parte aérea; portanto alocam, no sistema radicular, a maior proporção de produtos da fotossíntese. Quando há deficiência severa de nitrogênio a adição deste nutriente deve resultar em acréscimo na massa seca de raiz; por outro lado, se o fornecimento é muito elevado a massa seca de raiz tende a ser reduzida (Whitehead, 1995).

A razão MSPA/MSR variou de 0,91 a 2,05 (Figura 6), demonstrando maior proporção de massa seca de parte aérea em solo com alta disponibilidade de nitrogênio, porém Olsthoorn et al. (1991) observaram que quando a disponibilidade de nitrogênio é alta para as plantas de trigo nos estádios iniciais do crescimento e desenvolvimento, ocorre redução na relação à MSPA/MSR modificando a arquitetura das plantas e favorecendo o acamamento.

Chun et al. (2005) afirmam que a diminuição da relação MSPA/MSR é uma resposta adaptativa das plantas visto que em baixas concentrações de nitrogênio ocorrem redução de crescimento da biomassa da parte aérea e aumento da biomassa radicular para maximizar a capacidade da planta em absorver maior quantidade de nitrogênio do solo.

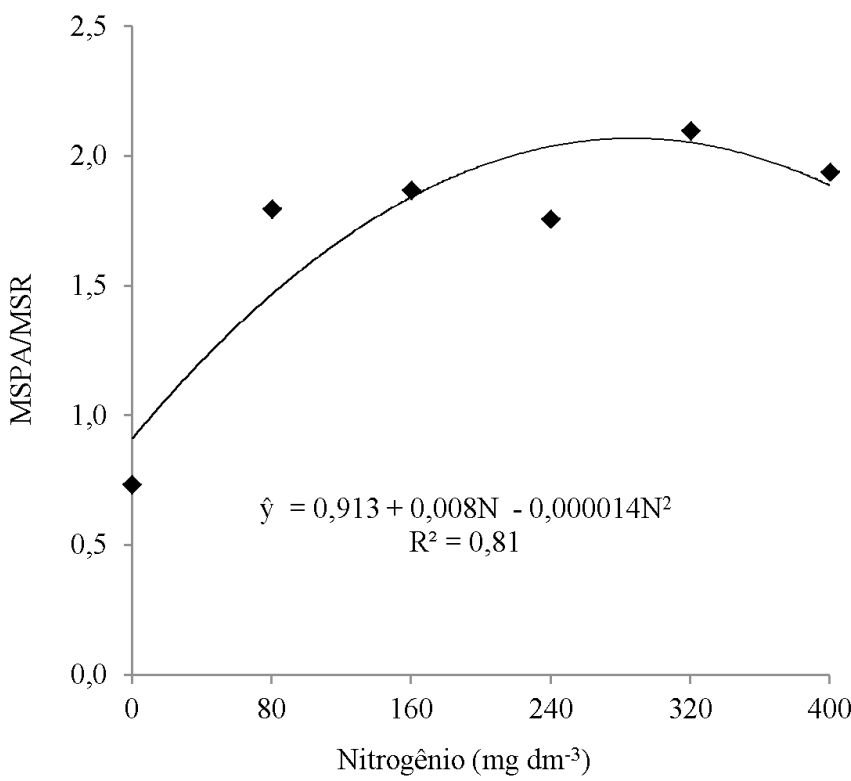

Figura 6. Relação massa seca da parte aérea e raiz (MSPA/MSR) de planta de trigo aos 47 dias de crescimento em função das doses de nitrogênio em Latossolo Vermelho de Cerrado

Soares et al. (2009) obtiveram, em média, em estudo com genótipos de milho submetidos a doses de nitrogênio, 2,77 de relação MSPA/MSR, sendo superior ao observado no presente trabalho em que a relação foi de 2,06. Rodrigues et al. (2007) porém, não encontraram influência da adubação nitrogenada na relação parte aérea-raiz em capim-xaraés.

\section{ConclusõEs}

1. A adubação nitrogenada influencia, de forma positiva, o desenvolvimento do trigo nos quatro períodos de avaliação.

2. As melhores respostas do trigo à adubação nitrogenada ocorrem nas doses de nitrogênio entre 80 a 195,6 $\mathrm{mg} \mathrm{dm}^{-3}$.

3. A relação massa seca da parte aérea/raiz é influenciada pela adubação nitrogenada com maior crescimento da parte aérea comparada com a raiz.

\section{Literatura Citada}

Bonfim-Silva, E. M.; Monteiro, F. A. Nitrogênio e enxofre em características produtivas do capim-braquiária proveniente de área de pastagem em degradação. Revista Brasileira de Zootecnia, v.35, p.1289-1297, 2006.

Bredemeier, C.; Mundstock, C. M. Estádios fenológicos do trigo para a adubação nitrogenada em cobertura. Revista Brasileira de Ciências do Solo, v.25, p.317-323, 2001.

Cazetta, D. A.; Fornasieri Filho, D.; Arf, O. Resposta de cultivares de trigo e triticale ao nitrogênio no sistema de plantio direto. Científica, v.35, p.155-165, 2007

Chun, L.; Mi, G.; Li, J.; Chen, F.; Zhang, F. Genetic analysis of maize root characteristics in response to low nitrogen stress Plant and Soil, v.276, p.369-382, 2005.

Coelho, M. A. O.; Souza, M. A.; Sediyama, T.; Ribeiro, A. C.; Sediyama, C. S. Resposta da produtividade de grãos e outras características agronômicas do trigo Embrapa-22 irrigado ao nitrogênio em cobertura. Revista Brasileira de Ciência do Solo, v.25, p.555-561, 1998.

CONAB - Companhia Nacional de Abastecimento. Acompanhamento da safra brasileira - grãos: Safra 2010/2011. Brasília: CONAB, 2011. 41p.

Cruz, J. L.; Pelacani, C. R.; Carvalho, J. E. B. de; Souza Filho, L. F. da S.; Queiroz, D. C. Níveis de nitrogênio e a taxa fotossintética do mamoeiro "Golden". Ciência Rural, v.37, p.64-71, 2007.

EMBRAPA - Empresa Brasileira de Pesquisa Agropecuária. Centro Nacional de Pesquisa de Solos. Sistema brasileiro de classificação de solos. 2.ed. Rio de Janeiro: Embrapa Solos, 2006. 306p.

Espindula, M. C.; Rocha, V. S.; Souza, M. A. de; Grossi, J. A. S.; Souza, L. T. de. Doses e formas de aplicação de nitrogênio no desenvolvimento e produção da cultura do trigo. Ciência e Agrotecnologia, v.34, p.1404-1411, 2010.

Ferreira, D. F. Sisvar: Um programa para análises e ensino de estatística. Revista Científica Symposium, v.6, p.36-41, 2008.

Fioreze, L. S. Comportamento produtivo do trigo em função da densidade de semeadura e da aplicação de reguladores vegetais. Botucatu: UNESP, 2011. 86p. Dissertação Mestrado

Lemaire, G.; Herbert, Y.; Charrier, X. Nitrogen uptake capacities of maize and sorghum crops in different nitrogen and water supply conditions. Agonomie, v.16, p.231-246, 1997.

Martuscello, J. A.; Fonseca, D. M.; Nascimento Júnior, D. do; Santos, P. M.; Cunha, D. N. F. V. C.; Moreira, L. M. Características morfogênicas e estruturais de capim-massai submetido a adubação nitrogenada e desfolhação. Revista Brasileira Zootecnia, v.35, p.665-671, 2006. 
Megda, M. M.; Buzetti, S.; Andreotti, M.; Teixeira Filho, M. C. M.; Vieira, M. X. Resposta de cultivares de trigo ao nitrogênio em relação às fontes e épocas de aplicação sob plantio direto e irrigação por aspersão. Ciência e Agrotecnologia, v.33, p.1055-1060, 2009.

Meneghin, M. F. S.; Ramos, M. L. G.; Oliveira, S. A. de; Ribeiro Júnior, W. Q.; Amabile, R. F. Avaliação da disponibilidade de nitrogênio no solo para o trigo em latossolo vermelho do Distrito Federal. Revista Brasileira de Ciência do Solo, v.32, p.1941-1948, 2008.

Olsthoorn, A. F. M.; Keltjens, W. G.; Baren, B.; Hopman, M .C. G. Influence of ammonium on fine root development and rhizosphere $\mathrm{pH}$ of Douglas-fir seedlings in sand. Plant and Soil, v.133, p.75-81, 1991.

Penckowski1, L. H.; Zagonel, J.; Fernandes, E. C. Nitrogênio e redutor de crescimento em trigo de alta produtividade. Acta Scientiarum. Agronomy, v.31, p.473-479, 2009.

Pöttker, D.; Roman, E. S. Efeito do nitrogênio em trigo cultivado após diferentes sucessões de culturas. Pesquisa Agropecuária Brasileira, v.33, p.501-507, 1998.

Ramos, M. Efeitos do nitrogênio e fósforo sobre características agronômicas da variedade de trigo IAS 54 e suas relações com a produção. Pesquisa Agropecuária Brasileira, v.8, p.213-216, 1973.

Ribeiro Júnior, W. Q.; Ramos, M. L. G.; Amábile, R. F.; Ferraz, D. M. M.; Carvalho, A. M. de; Carvalho, J. G.; Albrecht, J. C.; Silva, M. S; Guerra, A. F. Efeito da fertirrigação nitrogenada no rendimento de grãos de genótipos de trigo, no cerrado. Passo Fundo: Embrapa Trigo, 2007. 17p.

Rodrigues, R. C.; Mourão, G. B.; Valinote, A. C.; Herling, V. R. Reservas orgânicas, relação parte aérea-raiz e c-n e eliminação do meristema apical no capim-Xaraés sob doses de nitrogênio e potássio. Ciência Animal Brasileira, v.8, p.505-514, 2007.
Schröder, J. J.; Neeteson, J. J.; Oenema, O.; Struik, P. C. Does the crop or the soil indicate how to save nitrogen in maize production?: Reviewing the state of the art. Field Crops Research, v.66, p.151-164, 2000.

Silveira, C. P.; Oliveira, D. A. de; Bonfim-Silva, E. M.; Monteiro, F. A. Two years of nitrogen and sulfur fertilizations in a signal grass pasture under degradation: changes in the root system. Revista Brasileira de Zootecnia, v.40, p.1195-1203, 2011.

Soares, M. O.; Marriel, I. E.; Magalhães, P. C.; Guimarães, L. J. M.; Cantão, F. R. O.; Rocha, M. C.; Carvalho Júnior, G. A.; Miranda, G. V. Discriminação de linhagens de milho quanto à utilização de nitrogênio, por meio de avaliação de características do sistema radicular. Revista Brasileira de Milho e Sorgo, v.8, p.93-103, 2009.

Teixeira Filho, M. C. M.; Buzetti, S.; Alvarez, R. C. F.; Freitas, J. G.; Arf, O.; Sá, M. E. Resposta de cultivares de trigo irrigados por aspersão ao nitrogênio em cobertura na região do Cerrado. Acta Scientiarum Agronomy, v.29, p.421-425, 2007.

Teixeira Filho, M. C. M. T; Buzetti, S.; Andreotti, M.; Arf, O.; Benett. C. G. S. Doses, fontes e épocas de aplicação de nitrogênio em trigo irrigado em plantio direto. Pesquisa Agropecuária Brasileira, v.45, p.797-804, 2010.

Trindade, M. G.; Stone, L. F.; Heinemann, A. B.; Cánovas, A. D.; Moreira, J. A. A. Nitrogênio e água como fatores de produtividade do trigo no cerrado. Revista Brasileira Engenharia Agrícola Ambiental, v.10, p.24-29, 2006.

Viana, E. M.; Kiehl, J. C. Doses de nitrogênio e potássio no crescimento do trigo. Bragantia, v.69, p.975-982, 2010.

Whitehead, D. C. Grassland nitrogen. Wallingford: CAB International, 1995. 397p.

Yano, G. T.; Takahashi, H. W.; Watanabe, T. S. Avaliação de fontes de nitrogênio e épocas de aplicação em cobertura para o cultivo do trigo. Semina: Ciências Agrárias, v.26, p.141-148, 2005. 